$$
\text { DOE }\left.\right|_{\mathrm{DE} 92008702} ^{\mathrm{DOE} / \mathrm{PC} / 88818--11}
$$

TWO-STAGE, CLOSE COUPLED

CATALYTIC LIQUEFACTION OF COAL

ELEVENTH QUARTERLY REPORT FOR THE PERIOD

1 APRIL 1991 - 30 JUNE 1991
A.G. COMOLLI
E.S. JOHANSON
S.V. PANVELKER
G.A. POPPER
R.H. STALZER

WORK PERFORMED UNDER CONTRACT

DE-AC22-88PC88818

HYDROCARBON RESEARCH, INC.

100 OVERLOOK CENTER, SUITE 400

PRINCETON, NEW JERSEY 08540

OCTOBER 1991

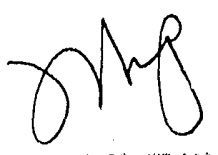


TWO-STAGE, CLOSE COUPIED

CATALYTIC LIQUEFACTION OF COAL

ELEVENTH QUARTERLY REPORT FOR THE PERIOD

1 APRIL 1991 - 30 JUNE 1991
A.G. COMOLLI
E.S. JOHANSON
S.V. PANVELKER
G.A. POPPER
R.H. STALZER

WORK PERFORMED UNDER CONTRACT

DE-AC22-88PC88818

HYDROCARBON RESEARCH, INC.

100 OVERLOOK CENTER, SUITE 400

PRINCETON, NEW JERSEY 08540

OCTOBER 1991 


\section{PRINTED IN THE UNITED STATES OF AMERICA}

AVAILABLE FROM:

National Technical Information Center

U. S. Department of Energy

5285 Port Royal Road

Springfield, Virginia 22161

This report was prepared as an account of work sponsored by the United States Government. Neither the United States nor the United States Department of Energy, nor any of their employees, makes any warranty, expressed or implied, or assumes any legal liability or responsibility for the accuracy, completeness, or usefulness of any information, apparatus, product, or process disclosed, or represents that its use would not infringe privately owned rights. Reference herein to any specific commercial product, process, or service by trade name, mark, manufacturer, or otherwise, does not necessarily constitute or imply its endorsement, recommendations, or favoring by the United States Government or any agency thereof. The views and opinions of authors expressed herein do not necessarily state or reflect those of the United States Government or any agency thereof. 


\section{TABLE OF CONTENTS}

PAGE

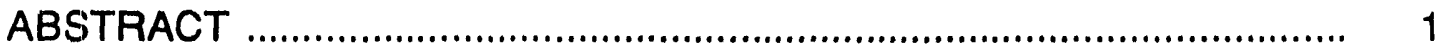

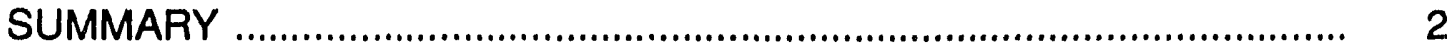

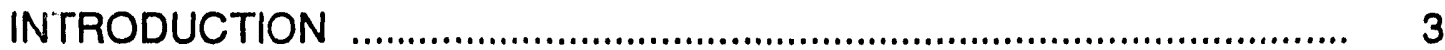

TASK 2 -LABORATORY SCALE STUDIES …………........................... 4

Evaluation of Rejuvenated/Regenerated Catalysts ..................... 4

Evaluation of Recovered Catalysts ............................................ 8

TASK 3 -BENCH-SCALE STUDIES ............................................. 10

Run CC-13 - $\mathrm{CO}_{2}$ Coal Studies .............................................. 10

Run CC-14 - Evaluation of a Pre-Dispersed Iron Oxide

Hydroxide Catalyst .................................................................. 12

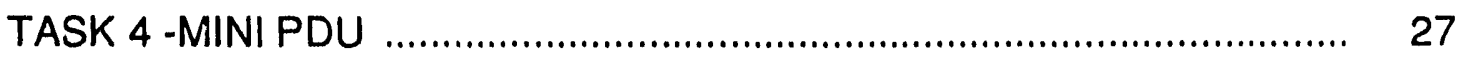

TASK 5 -TECHNOLOGY ASSESSMENT .......................................... 27

TASK 6 -ADMINISTRATION .......................................................... 28 


\section{ABSTRACT}

This quarterly report covers activities of the Two-Stage, Close-Coupled Catalytic Liquefaction of Coal program during the period April 1, - June 30, 1991, at Hydrocarbon Research, Inc., in Lawrenceville and Princeton, New Jersey. This DOE contract period is from October 1, 1988 to December 31, 1991.

The overall purpose of the program is to achieve higher yields of better quality transportation and turbine fuels and to lower the capital and production costs in order to make the products from direct coal liquefaction competitive with other fossil fuel products.

The quarterly report covers work on Microautoclave Testing, Bench-Scale experimentation, Technology Assessmient, Modelling and scheduling. 


\section{SUMMARY}

The second calendar quarter of 1991 concluded a series of bench-scale studies prior to a PDU run on Wyoming Black Thunder coal.

In Laboratory Scale Studies, rejuvenated and regenerated catalysts were evaluated and compared at various stages of preparation. The rejuvenated catalyst compared favorably with fresh catalyst. Spent catalysts from the Bench-Scale evaluation of rejuvenated catalyst were also examined on a micro-autoclave scale along with catalysts from previous bench studies.

A $201 / 3$ day run was completed evaluating a PETC catalyzed coal using a pre-dispersion technique to precipitate iron catalyst on the coal and comparing its performance with molybdenum catalyzed and thermal operation.

Performance of the iron oxide hydroxide catalyst was very good at mild conditions, comparing favorably with molybdenum and supported catalyst.

The mini PDU run is scheduled to occur in the October-November time frame. 


\section{INTRODUCTION}

The studies conducted in this, the eleventh quarterly report of Contract No. DE-AC22-88PC88818, are reported by task and in sequence.

Task 1 is the Management Plan and is complete. Task 2 is for Laboratory Studies and includes microautoclave and microreactor work. Task 3 is for Bench-Scale studies and in this report covers results of Runs CC-12, and 13. Task 4 is for Mini PDU Scale-up. Task 5 is the Technical Assessment, including Modelling, Design and Economics. Task 6 is Administration.

The contract period was from October 1, 1988, to September 30,1991, and has been extended to December 31, 1991. 


\section{TASK 2 - LABORATORY STUDIES}

\section{EVALUATION REJUVENATED/REGENERATED CATALYSTS}

The rejuvenated CTSL catalyst charged to bench unit Run CC-12 has been evaluated in the microautoclave for residual oil conversion activity, hydrogen addition, and denitrogenation performance. The test program included comparison with the performances of fresh S-317 catalyst, the recovered CTSL catalyst used to prepare the rejuvenated catalyst, the acid-washed catalyst produced in the course of preparing the rejuvenated catalyst, regenerated cutalyst (without acid washing), acid washed catalyst regenerated to three different carbon contents, and recovered first and second stage catalysts from Run CC-12.

Table 1 summarizes the results of these microautoclave tests.

The program showed that the rejuvenated catalyst had catalytic performance very nearly that of fresh S-317 catalyst, acid washing alone had only a partial restoration of catalytic activity while regeneration (without acid washing) was very nearly as effective as the rejuvenation procedure, optimal regeneration might be at a lower severity than used in preparing the rejuvenated catalyst. The recovered second stage catalyst from Run $\mathrm{CC}-12$ was considerably more deactivated than the recovered first stage catalyst.

1) The recovered CTSL catalyst used in preparing the Rejuvenated used in Run CC- 12 was less active than fresh (presulfided) Catalyst (compare Runs CE32 and CE36):
A) Nominally $56 \%$ as active for residual oll conversion (relative first order rate constant - $\ln ($ Cfeed/Cprod));
B) The hydrogen content increased by only $0.26 \mathrm{~W} \%$ compared to $0.57 \mathrm{~W} \%$;
C) The nitrogen content was lowered by only $0.20 \mathrm{~W} \%$ compared to 0.37 W\%:

2) The activity of the rejuvenated catalyst charged to run CC-12 approached that of fresh catalyst (compare Runs CE 33 and CE36:

A) The nominal residual conversion activity was $93 \%$ that of fresh catalyst;

B) Hydrogen content was increased by $0.46 \mathrm{~W} \%$ (vs $0.57 \mathrm{~W} \%$ );

C) Nitrogen content was lowered by $0.39 \mathrm{~W} / \%$ (more than by fresh catalyst, $0.37 \mathrm{~W} \%) ;$

3) Acid Washing alone gave a relatively small improverient in catalyst performance (Run CE37):

A) The nominal residual oil conversion actlvity increased to $69 \%$ of fresh catalyst (from $56 \%$ ); 

B) The hydrogen content increase was $0.32 \mathrm{~W} \%$ (up from $0.26 \mathrm{~W} \%$ );
C) The nitrogen content was lowered by $0.23 \mathrm{~W} \%$ (compared to $0.20 \mathrm{~W} \%$ ):

4) Regeneration alone (without acid washing) resulted in catalyst performance very comparable to that of the rejuvenated catalyst (Run CE41):
A) The nominal residual oil conversion activity, at $97 \%$ of that of fresh catalyst, was slightly higher than that of the rejuvenated catalyst, $93 \%$;
B) The increase of hydrogen content, $0.42 \mathrm{~W} \%$, was slightly less than that with rejuvenated catalyst, $0.46 \mathrm{W \%}$;
C) The decrease in nitrogen content, $0.31 \mathrm{~W} \%$, was appreciably less than that with rejuvenated catalyst, $0.39 \mathrm{W \%}$;

5) A serles of tests with acid washed catalyst regenerated to various carbon contents indicated the following (Rins CF 38, CE39, and CE40). These samples were from the various batchies of regenerated material combined as the L-759 composite:

A) Lowering the carbon content to $9.0 \mathrm{~W} \%$, from $18.7 \mathrm{~W} \%$, resulted in only partial recovery of catalytic activity, to $82 \%$ of fresh catalyst residual oil conversion activity, and comparable performance with regard to hydrogen uptake and nitrogen removal;

B) The regenerated sample with $4.0 \mathrm{~W} \%$ carbon gave the highest residual oil conversion activity, almost exactly equal to that of the fresh catalyst. However, hydrogen addition and denitrogenation were slightly below that of the fresti catalyst or of the rejuvenated composite, which contained 0.73 W\% carbon.

C) The regenerated sample containing $1.55 \mathrm{~W} \%$ carbon had values of the three performance parameters very close to those with the composited L-759 rejuvenated catalyst. This degree of agreement might be regarded as the reproducibility of the test procedure.

6) The first and second stage catalysts recovered after CTSL Run CC-12 were also evaluated in the microautoclave with the following results (Runs CE34 and CE35);

A) The second stage catalyst had been appreciably more deactivated than the first stage catalyst to $45 \%$ of fresh catalyst residual oil conversion activity compared to $70 \%$ for the first stage catalyst, and only $0.19 \mathrm{~W} \%$ hydrogen addition compared to $0.38 \%$ for the first stage catalyst. The product nitrogen contents were the same for these two tests, but very small effects would be expected after considering the results of the other microautoclave tests; 
B) The averages of the three performance parameters for first and second stage catalysts from Run CC- 12 were very close to the performance parameters for the original L-758 recovered catalyst (which was a composite of first and second stage catalysts) used in preparing the rejuvenated catalyst. This result indicates no extraordinarily great rate of deactivation for the rejuvenated catalyst, although the Run CC-12 operation processed $325 \mathrm{lbs}$ coal//b catalyst/stage, while the operations of the CTSL recovered catalyst used in preparing the rejuvenated catalyst charge to Run CC-12 had processed about 1121 pounds coal per pound of catalyst in a sequence of runs. 


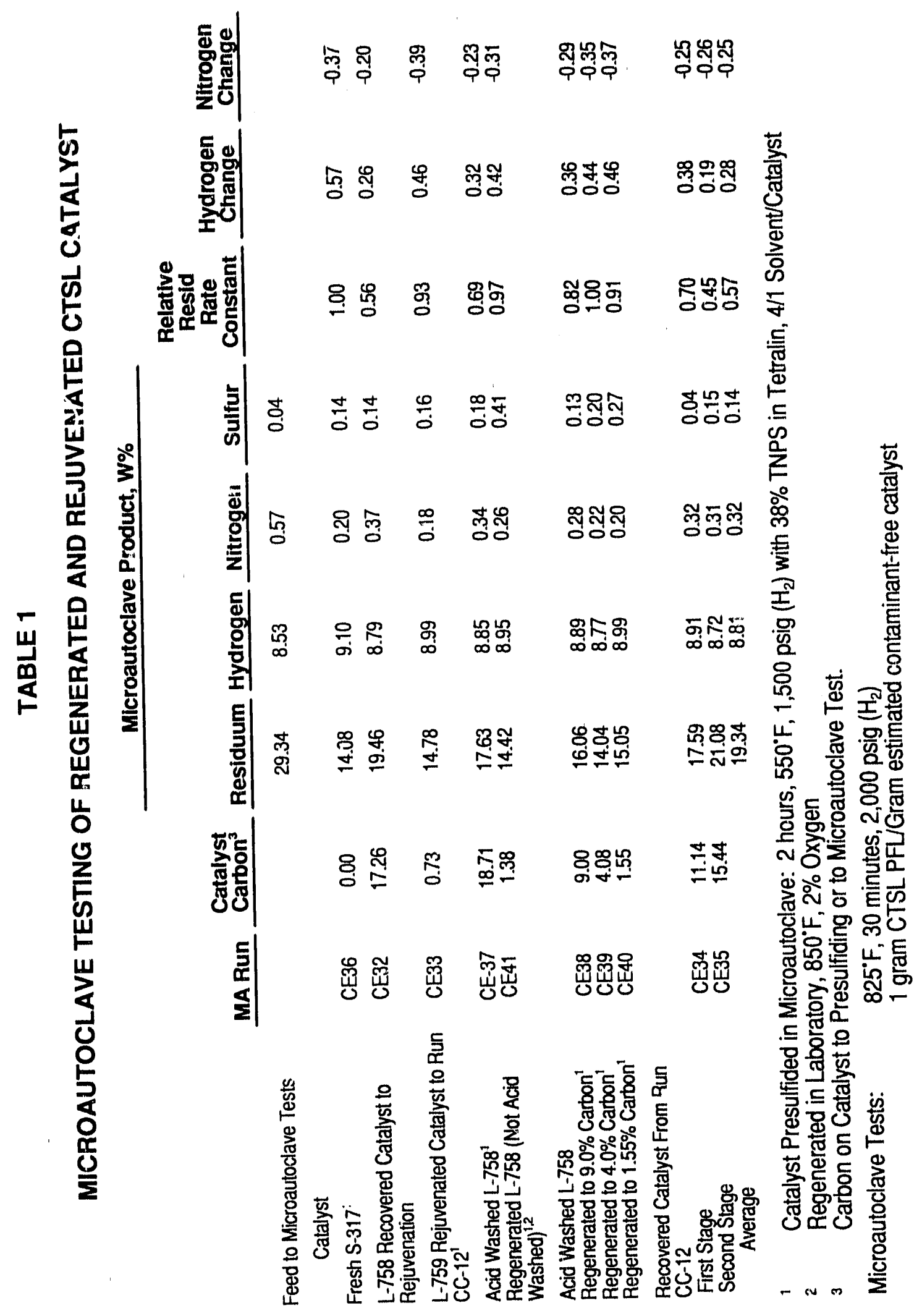




\section{EVALUATION OF RECOVERED CTSL CATALYSTS}

In addition to the evaluation of the first and second stage catalysts from CTSL Run CC. 12, which was discussed in the section above, first and second stage catalysts from Runs CC-8, and CC- 11 were similarly evaluated in the microautoclave. Table 2 summarizes the results of these microautoclave tests.

CTSL Bench Unit Run CC-8 processed Illinols No. 6 Coal that had been cleaned by the Otisca Process to reduce the ash content to $3.5 \mathrm{~W} \%$. CTSL Bench Unit Run CC-11 processed Black Thunder Mine (Wyoming) coal. The catalyst for both runs was Shell S-317 catalyst, which was presulfided, using TNPS doped gas-oil at temperatures of $450-650^{\circ} \mathrm{F}$, as part of the start-up operations of the run. During Run CC- $11 \mathrm{H}_{2} \mathrm{~S}$ was added, corresponding to $2 \mathrm{~W} \%$ of the coal, so as to inaintain the sulfided level of the catalyst. $\mathrm{No} \mathrm{H}_{2} \mathrm{~S}$ was added during Run $\mathrm{CC}-8$ since with the higher sulfur content Illinois Coal the $\mathrm{H}_{2} \mathrm{~S}$ formation was equivalent to this proportion.

The current microautoclave tests included a contemporary series of tests using Shell S-317 catalyst, HRI 5394P, which had been pie-sulfided somewhat similarly to the CTSL Bench Unit procedure, although in a small fixed bed. This series of tests was intended to supply a reference data base for "fresh" catalyst to use in comparison with the results for the recovered CTSL catalysts.

Referring to Table 2, all four of the recovered catalysts showed appreciable activity in converting the residual component in a recycle solvent obtained during CTSL Bench Unit operations with Black Thunder Mine coal in Run CC-1. The residual oll conversion levels with the recovered catalysts were higher than obtained with half as much "fresh" catalyst, but lower, in three cases, than obtained with about the same amount of "fresh" catalyst. The first and second stage calalysts from Run CC-8 had about the same catalyst effectiveness, $77-83 \%$ of that of "fresh" catalyst as these microautoclave tests have been correlated. In contrast, the first stage catalyst from Run CC-11 was considerably more effective than the second stage catalyst from that run. Actually, this first stage catalyst demonstrated an activity even higher than that of the "fresh" catalyst, while the second stage catalyst was only $71 \%$ as effective as the "fresh" catalyst.

The relative effectiveness of the four recovered catalyst that were tested corresponded to their carbon contents (noted in Table 2), with the least effective catalyst containing $18.8 \%$ carbon, and the most effective $10.0 \%$ carbon, and the catalysts of intermediate effectiveness having intermediate carbon contents.

There were a pair of replicate tests with the "fresh" catalyst, Runs CM103 and CM105, which indicates the sensitivity of the microautoclave tests to the analytical results, where a difference of less than $1 \mathrm{~W} \%$ in analyzed residual oil content corresponds to a difference of over $20 \%$ in indicated catalyst effectiveness. This is because the conversion pattern with increasing catalyst/oil ratio does not follow simple first-order kinetics so that deeper residual conversions require disproportionate increases in catalyst effectiveness. The correlating equations indicated in Table 2 correspond to system with two residual oil components of differing reactivity, both following first-order kinetics. 


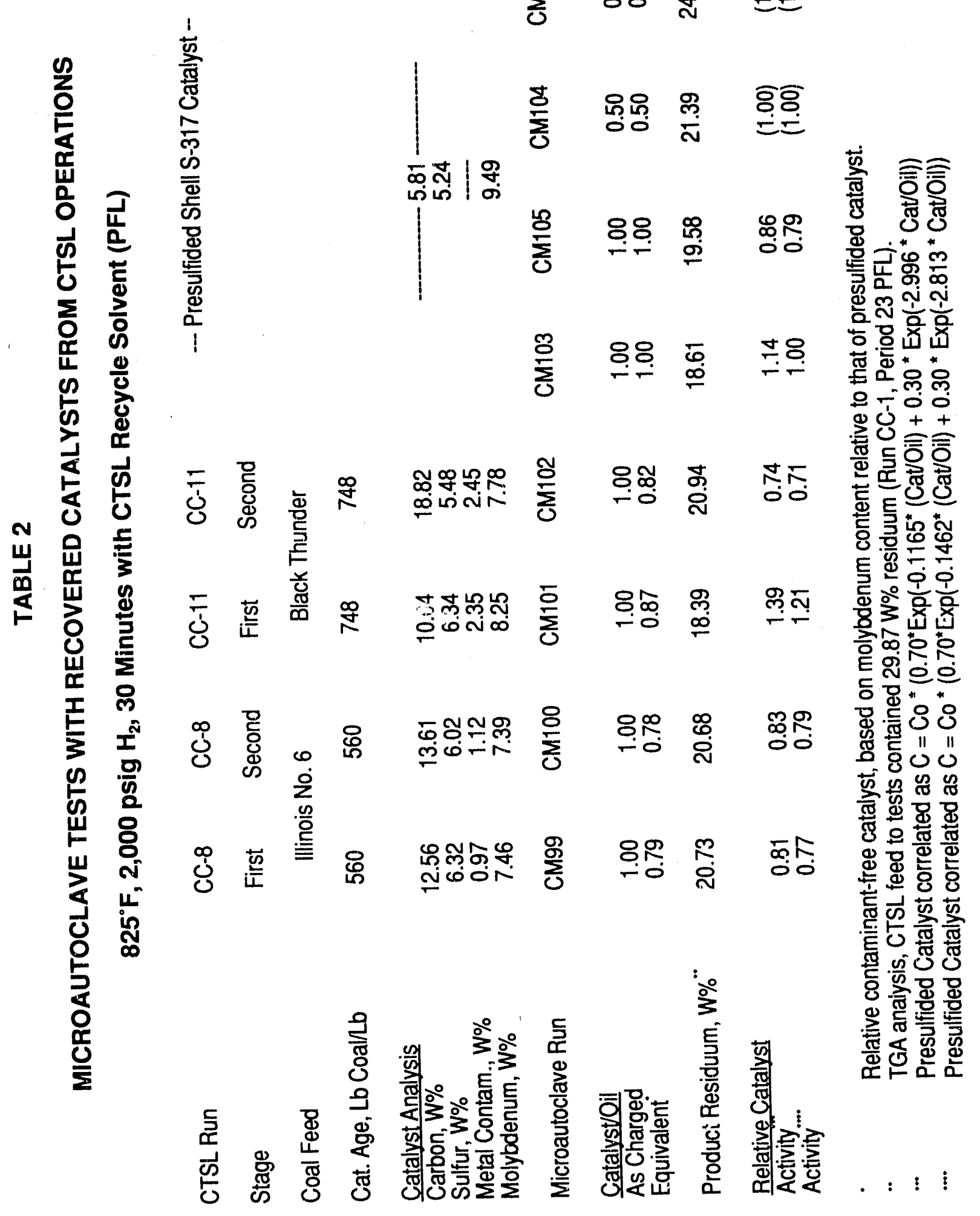

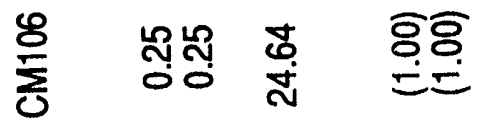

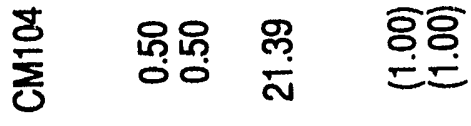

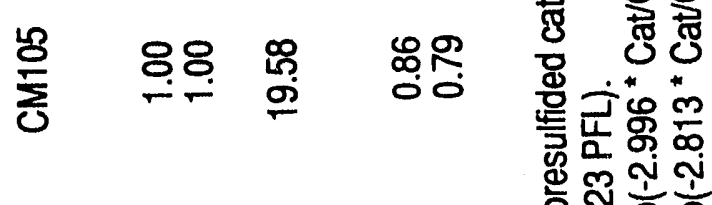

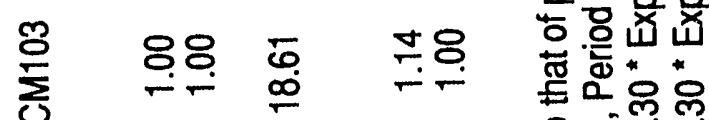

두우

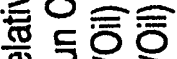

엉

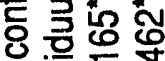

잉ㅎㅇ

a 


\section{TASK 3 - BENCH SCALE STUDIES}

\section{RUN CC-13 (227-71) CO2 AND LIGHT DISTILLATE SLURRYING}

The principal results of Run $\mathrm{CC}-13$, which evaluated $\mathrm{CO}_{2}$ or a vaporizable distillate as feed slurrying agents for Black Thunder Mine coal in the CTSL process, were summarized in the previous Quarterly Report. The analyses of the first and second stage catalysts recovered after the operations of that run have become available, and are summarized in Table 3.

The catalysts from both stages recovered after Run CC-13 were highly contaminated, with carbon contents higher than contained on the corresponding catalysts recovered after previous CTSL runs with Black Thunder Mine coal. The first stage catalyst contained $17.6 \mathrm{~W} \%$ carbon, which compares to values of $15.6 \%$, $11.4 \%, 8.9 \%, 13.6 \%, 10.0 \%$, and $11.4 \%$ for recovered first stage catalysts after the eartier runs with Black Thunder Mine coal. The second stage catalyst after Run CC-13 contained $31.4 \mathrm{~W} \%$ carbon, which is exceptionally high compared to values of $18.9 \%, 13.1 \%, 18.2 \%, 18.8 \%$, and $15.4 \%$ for second stage catalysts after those earlier runs. It does not appear that these Run CC-13 carbon accumulations were associated with loss of ebullation during the run since the unit was operating in good order with a slightly elevated pressure drop during the final coal operations and the subsequent shut-down operations. The catalysts were in the normal settled positions in the reactor and recovered from the reactors as loose extrudates, although there was a thin plug about half way up in the settled bed in the second stage reactor and a small amount of catalyst in the screen at the top of the that reactor. The elevation in pressure drop from a norma! level of about 3 psi to about 20 psi across the second stage reactor first appeared during the twelfth day of the run during the attempted operations using a light distillate $\left(480^{\circ} \mathrm{F}\right.$ average boiling point) for slurrying the coal in place of recycled filtered liquid. This elevated pressure drop persisted with the returned to normal slurrying practice in the thirteenth day to the end of run after 19 days.

There was a considerable loss in pore volume and surface area associated with the very high carbon accumulation on the recovered second stage catalyst, with a pore volume about one-third, and surface area one-tenth, of that of fresh catalyst. 
TABLE 3

RECOVERED CATALYST ANALYSIS

RUN 227-71 (CC-13)

STAGE

\begin{tabular}{|c|c|}
\hline First & Second \\
\hline 541 & 537 \\
\hline $\begin{array}{r}775 \\
637 \\
0.821\end{array}$ & $\begin{array}{r}680 \\
760 \\
1.118\end{array}$ \\
\hline
\end{tabular}

Catalyst Age, Lb Coal/Lb

Catalyst Recovery

Volume (compacted), cc

Weight, grams

0.821

1.118

Analyses of Cill-Free +20 Mesh Catalyst. W\%

Carbon

17.60

Hydrogen

$\mathrm{H} / \mathrm{C}$ Ratio

Nitrogen

1.12

31.44

Sulfur

0.76

0.97

0.30

Molybdenum

5.43

Nickel

7.52

Titanium

1.63

0.03

Iron

0.45

Calcium

0.59

Sodium

Total Metal Contaminants

0.82

1.89

0.37

0.23

5.26

Loss on Ignition, W\%

20.44

5.95

1.28

0.02

0.10

0.29

Particle Density, Gm/cc particle ${ }^{\circ}$

1.329

0.296

0.393 $\mathrm{cc} / \mathrm{cc}$ particle

Surface Area (calc.), $\mathrm{M}^{2} / \mathrm{gm}$ $\mathrm{M}^{2} / \mathrm{cc}$ particle

40.98

Pore Volume ( $\left.>30^{\circ} \mathrm{A}\right), \mathrm{cc} / \mathrm{gm}$

1.655

0.124

0.205

187

Modal Pore Diameter. Angstron Miacro-pores

Mini-pores

1,930

61

Analysis of lgnited Catalyst

Particle Density, Gm/cc particle ${ }^{\circ}$

$1.069 \quad 1.080$

Pore Volume $\left(\mathrm{D}>30^{\circ} \mathrm{A}\right), \mathrm{cc} / \mathrm{gm}$ cc/cc particle

Surface Area (calc.), $\mathrm{M}^{2} / \mathrm{gm}$ $\mathrm{M}^{2} / \mathrm{cc}$ particle

0.557

0.563

0.595

204

218

0.608

190

Modal Pore Diameter. Angstron Macro-pores

Mini-pores

2,190

9

96

Analysis of -100 Mesh Oil-Free Solids

Weight, Grams

Molybdenum, W\%

1.53

3.52

Analysis of -100 Mesh Oil-Free Solids

Weight, Grams

Molybdenum, W\%

0.31

- In mercury at 10 psia 


\section{RUN CC-14 - EVALUATION OF A PRE-DISPERSED IRON OXIDE HYDROXIDE CATALYST}

A201/3 day study was conducted with a pre-dispersed iron-oxide hydroxide catalyst that included a comparison with molybdenum and a non-catalytic operation.

\section{EXPERIMENTAL PLAN}

The original plan specified an 18 day operation, however due to a mid-run flow interruption, the operation was extended to $201 / 3$ days at five conditions, three with $\mathrm{FeOOH}$, one with no additive and one with Ammonium Tetrathio-Molybdate added to the slurry. The space velocity, backpressure, $\mathrm{H}_{2} \mathrm{~S}$ addition rate, second stage temperature and oil/coal ratio were held constant throughout the run after initial adjustment early in condition 1 of the feed slurry concentration. A preheater temperature of $527^{\circ} \mathrm{F}\left(275^{\circ} \mathrm{C}\right)$ was used. The original plan called for lowering the pretreater reactor temperature to less than $400^{\circ} \mathrm{F}$ during the condition with molybdenum based catalyst as the work at PETC indicated that the pretreatment was not required to activate the catalyst; however, it was necessary to operate at $527^{\circ} \mathrm{F}$ as a result of line plugging problems. 
TABLE 4

EXPERIMENTAL PLAN, CC-14

\section{EVALUATION OF DISPERSED CATALYST}

Condition

Periods

Dispersed Catalyst

Temperatures, ' $\mathrm{F}$

Pretreatment

Second Stage

Third Stage

Other

Pressure, Psig - 2,500

$\mathrm{H}_{2} \mathrm{~S}, \mathrm{~W} \%$ Coal $-3 \%$

Oil/Coal Ratio - 1.6

$\begin{array}{ccccc}1 & 2 & 3 & 4 & 5 \\ 1-5 & 6-10 \mathrm{~A} & 11 \mathrm{~A}-15 \mathrm{~A} & 15 \mathrm{~B}-18 \mathrm{~A} & 18 \mathrm{~B}-21 \mathrm{~A} \\ \mathrm{FeOOH} & \mathrm{FeOOH} & \text { ATTM } & \text { None } & \mathrm{FeOOH}\end{array}$

527

800

775

527
825
775

$450-525$
825
775

527

825

527

825

775

775 
COAL

The feed was an Illinois \#6. Burning Star Mine coal pulverized to -200 mesh (See Table 5). The catalyzed coal was prepared by DOE-PETC using an inciplent wetness impregnation/precipitiation method. A solution of one part ferric nitrate $\left(\mathrm{Fe}\left(\mathrm{NO}_{3}\right)_{3} \cdot 9 \mathrm{H}_{2} \mathrm{O}\right)$ dissolved in 40 parts distilled water was used to wet 50 parts of -200 mesh coal to inciplent wetness (paste). The wet coal paste was then added into a solution containing 20 parts ammonium hydroxide $\left(29 \% \mathrm{NH}_{3}\right)$ and 200 parts distllled water. This mixture was then pressure-filtered through 0.45 micron media to obtain a clear filtrate. The iron catalyzed coal was then vacuum dried at $104^{\circ} \mathrm{F}$.

Pulverized untreated Illinois coal was used for the baseline and for the molybdenum catalyzed bench unit conditions.

\section{CATALYSTS}

The supported catalyst in the second stage reactor was Shell 317, a commerclal NiMo 1/32" diameter extrudate with a bi-modal pore distribution. Dispersed catalysts were the precipitated $\mathrm{FeOOH}$ at $2,800 \mathrm{ppm} \mathrm{Fe}_{\theta}$ on a coal basis and molybdenum sulfide added at $10 \%$ solution in water as ammonlum tetrathiomolybdate. This was mixed into the coal feed slurry to obtain a moly concentration of $1,500 \mathrm{ppm}$ on a coal basis. 
TABLE 5

ILLINOIS \#6 COAL ANALYSIS

Ultimate, W\% Dry

\begin{tabular}{|c|c|}
\hline Treated & Untreated \\
\hline 68.78 & 68.6 \\
\hline 4.32 & 4.29 \\
\hline 3.19 & 3.39 \\
\hline 1.58 & 1.26 \\
\hline 11.00 & 10.83 \\
\hline 11.13 & 11.63 \\
\hline
\end{tabular}

Ash Analysic, W\% lanited

Silicon Dioxide

Aluminum Oxide

Potassium Oxide

Iron Oxide

Sulfur Trioxide

All others less than $1 \%$
46.3

18.1

1.7

20.6

5.4
47.1

17.9

1.8

17.2

7.3 


\section{OPERATIONS}

Following presulfiding of the sulfided NiMo catalyst with injected $\mathrm{H}_{2} \mathrm{~S}$ and an IIIinois coal derived heavy distillate, catalyzed coal was introduced and operations proceeded smoothly until an interruption of flow occurred during a planned transition to a lower temperature prior to condition 3. A line plug was removed and the unit restarted in one day, operations then were steady with the exception of some foaming from moist coal in condition 5 .

\section{PRODUCT YIELDS}

Coal conversion ranged from 94 to 95 W\% (MAF) as shown in Table 6. Dispersed catalyst had an insignificant effect on coal conversion. Interstage samples obtained after condition 2 through 5 indicated that all the coal conversion $\left(94^{+} \%\right)$ occurred in the second stage with the third stage performing residuum conversion and product upgrading.

The highest distillate yields $(74.5 \%)$ in the study were obtained in condition 1 with $\mathrm{FeOOH}$ dispersed coal at the least severe first stage $\left(800^{\circ} \mathrm{F}\right)$ temperature and the next highest in conditions 3 with the added molybdenum catalyst. Table 6 and Figure 1 and 2 attached show the performance at each operating condition. The unanticlpated poorer performance in condition 5 may have been the result of several factors; among these are: (1) the intermittent addition of moist coal impacting hydrogen partial pressure and (2) not achleving equllibrium following the uncatalyzed coal operation in condition 4. An indication of the latter is supported by the interstage samples taken at the end of each condition; these results are shown in Figure 3. Note that the $\mathrm{H} / \mathrm{C}$ ratio of the mid-distillate cuts is continuing to increase after condition 5 wille the $H / C$ ratio of the recycle PFL (pressure filter liquid) existing in the second stage is continuing to decrease, Figure 4. Further evidence of non-equillbrium operation is shown ir a plot of PFL sulfur content in Figure 5. The sulfur coritent of the distillate continues increasing in the thermal condition 4 through repeat $\mathrm{FeOOH}$ condition 5.

The yields in conditions 1 and 2, as shown in Figure 6, Illustrate the selectivity of $\mathrm{FeOOH}$ catalyst at two thermal severities. Light gas $\left(\mathrm{C}_{1}-\mathrm{C}_{3}\right)$ yield increases by nearly $4 \%$ and naphtha by nearly $5 \%$ resulting in increased hydrogen consumption, 8.2 vs $7.5 \%$ and lower total distillate production. The distillate yield increased by more than $2 \%$ when the catalyst was changed from $\mathrm{Fe}$ to Mo and decreased by more than $4 \%$ in the transition to no added dispersed catalyst in condition 4.

The quality of the liquid products from the run are exempllfied by the atmospheric still overhead products $\left(250-650^{\circ} \mathrm{F}\right.$ ) as shown in Table 7 . In terms of hydrogen content and heteroatom content, the best quality is found at conditions 1 and 3 with the $\mathrm{FeOOH}$ catalyst at mild conditions and with the molybdenum catalyst. 
TABLE 6

\section{CONTINUOUS BENCH-SCALE \\ EVALUATION OF DISPERSED FEOOH AND \\ AMMONIUM TETRATHIO-MOLYBDATE}

Condilition

Addilive

Amount

$\begin{array}{ccccc}1 & 2 & 3 & 4 & 5 \\ \mathrm{~F} \theta \mathrm{OOH} & \mathrm{F}_{\theta} \mathrm{OOH} & \text { ATTM } & \text { Norie } & \mathrm{F} \theta \mathrm{OOH} \\ 2,800 \mathrm{ppm} & 2,800 \mathrm{ppm} & 1,500 \mathrm{ppm} & \cdots & 2,800 \mathrm{ppm}\end{array}$

Reaction Temp. 'F

Pretreater

First Stage

Second Stage

Yields, W\% MAF Coal

$\mathrm{C}_{1}-\mathrm{C}_{3}$

$\mathrm{C}_{4}-390^{\circ} \mathrm{F}$

$390-650^{\circ} \mathrm{F}$

$650-975^{\circ} \mathrm{F}$

$975^{\circ} \mathrm{F}^{+}$

Performance, W\% MAF Coal

$\mathrm{C}_{4}-975^{\circ} \mathrm{F}$

$975^{\circ} \mathrm{F}^{+}$Conversion

Hydrogen Consump. W\%

Coal Conversion
8.6

20.7

34.9

19.5

5.7

527

825

775

523

822

775

775

12.3

26.5

32.3

10.2

3.6

75.1

88.0

7.5

94.0
69.0

90.4

8.2

94.6
11.5

24.0

33.1

14.7

4.6

71.8

89.5

8.1

94.5
528

822

774

527

825

774
$12.0 \quad 12.5$

$21.7 \quad 23.3$

$31.9 \quad 30.6$

$13.6 \quad 11.8$

$\begin{array}{ll}7.3 & 7.4\end{array}$ 
FIGURE 1

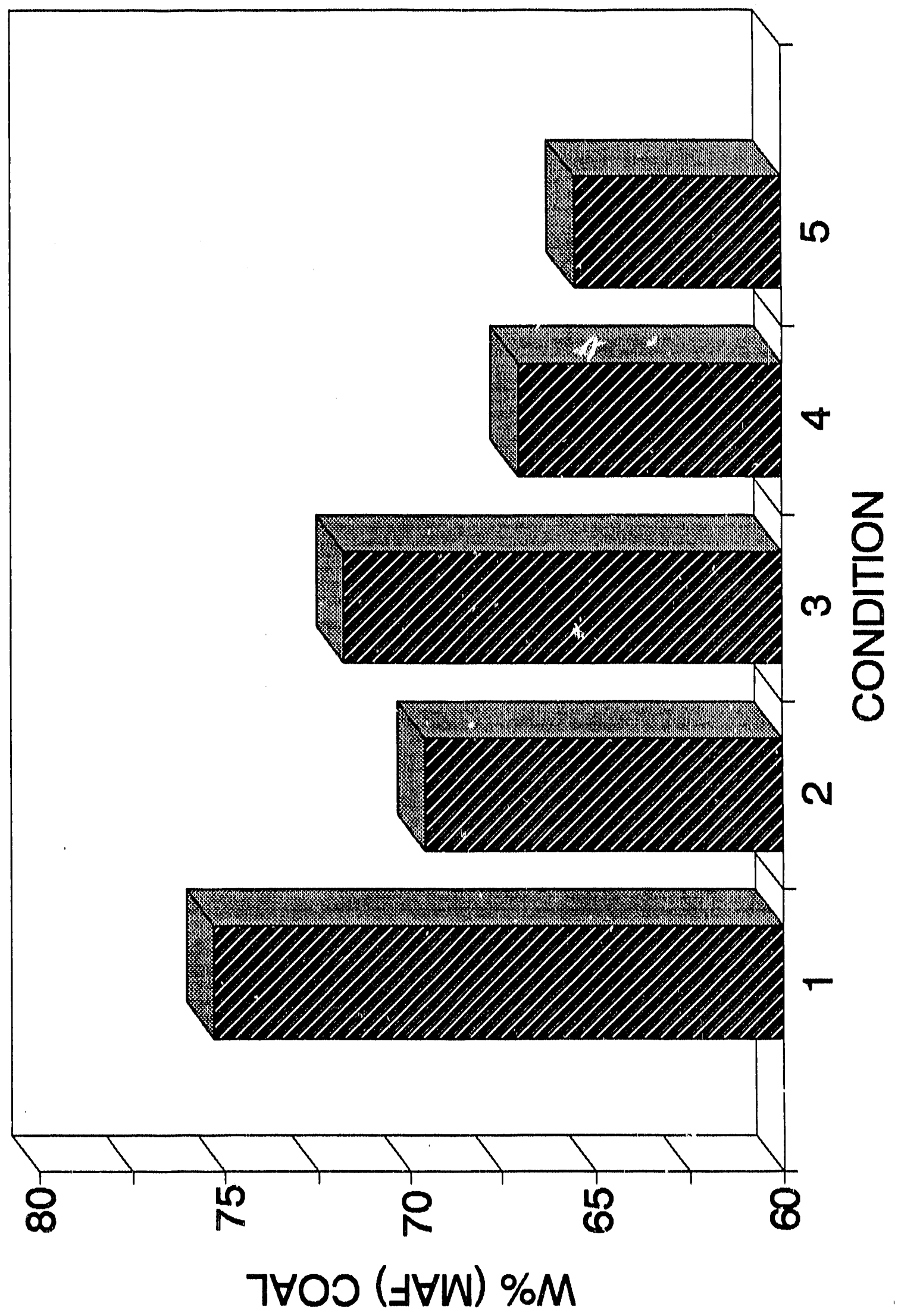


FIGURE 2

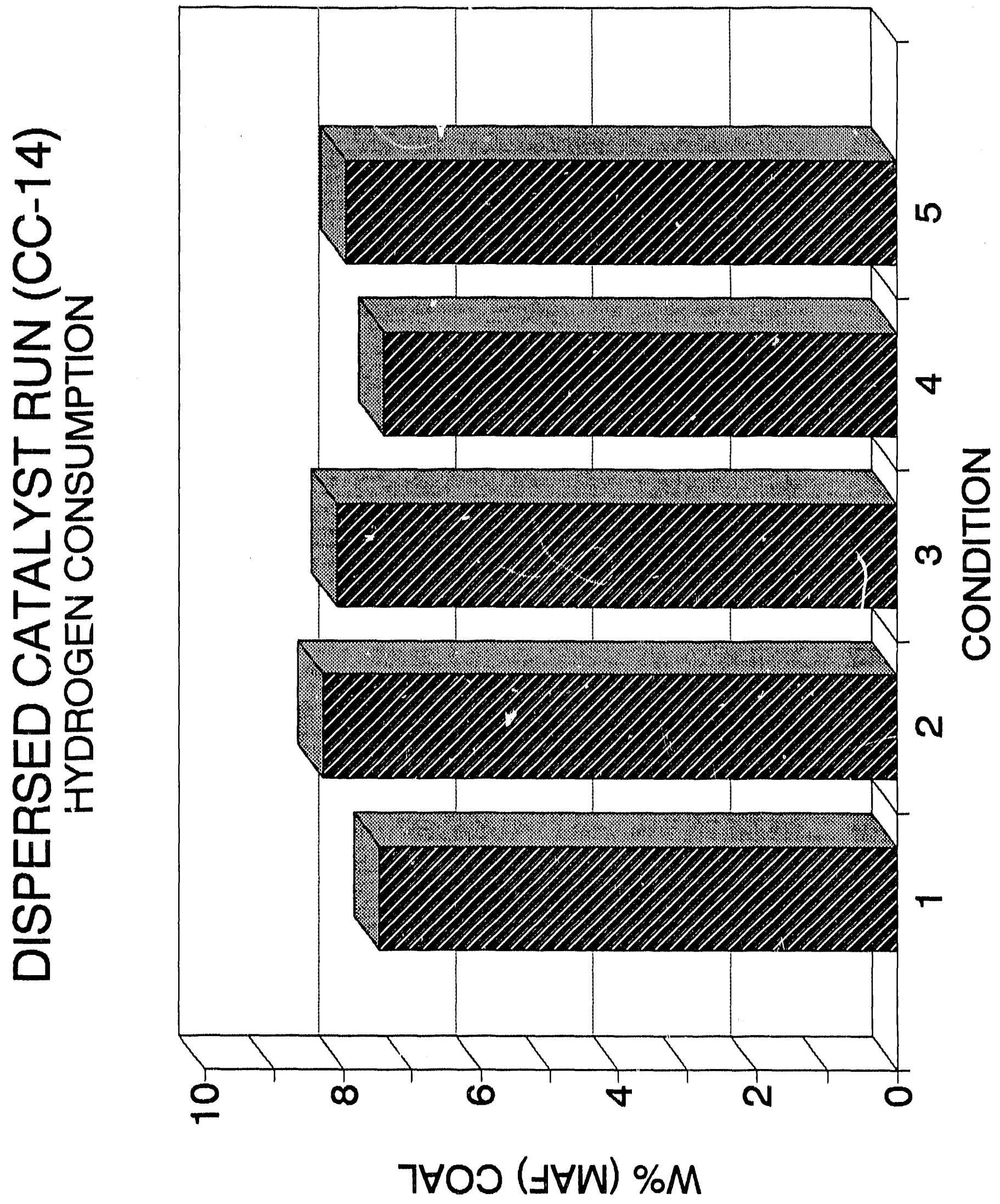




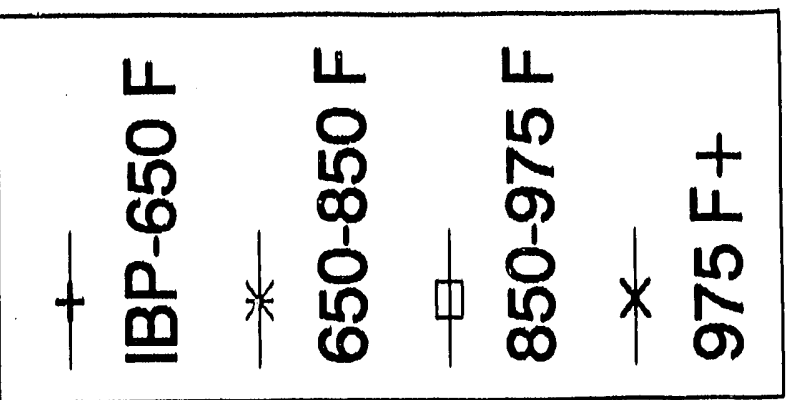

FIGURE 3
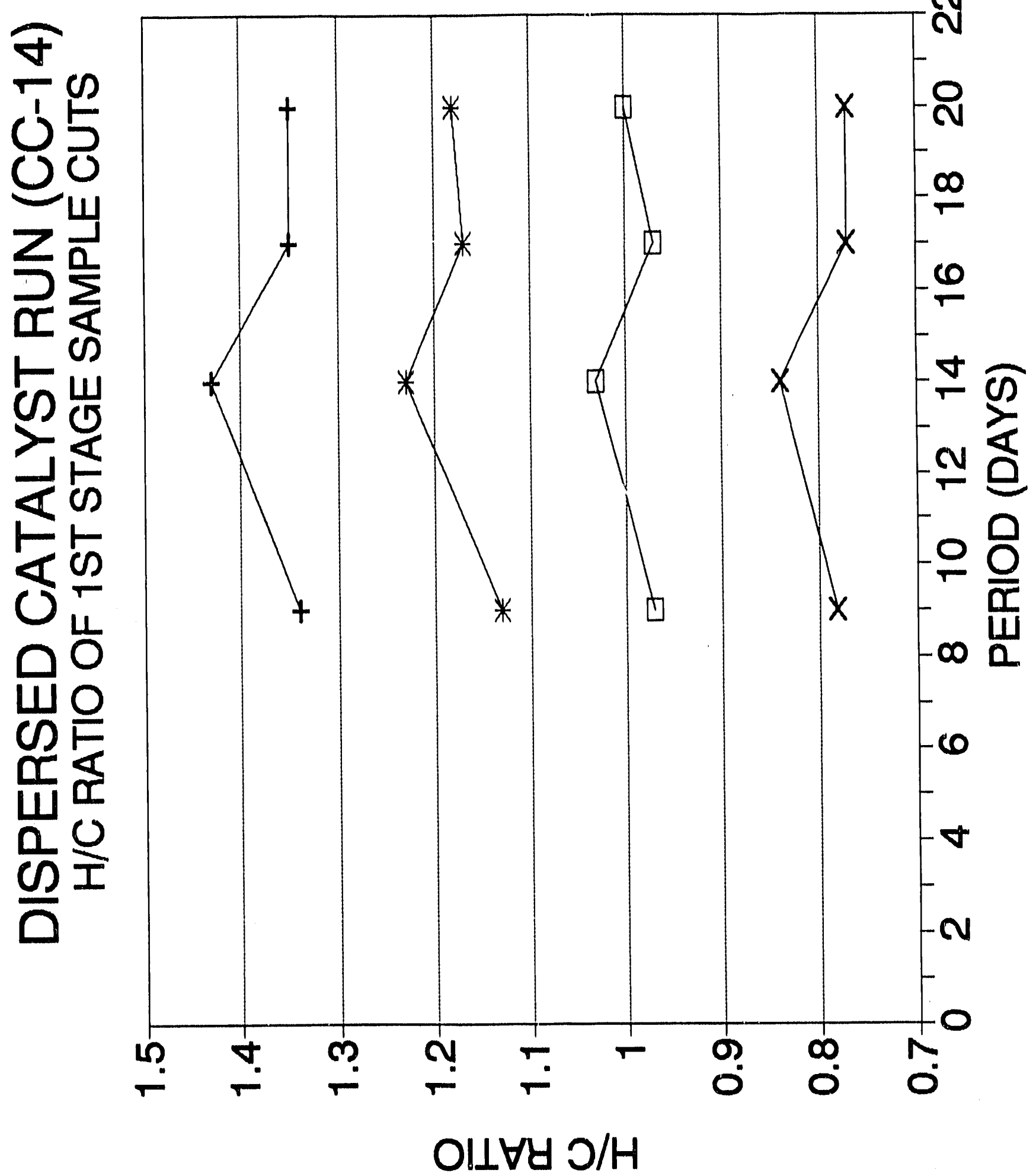


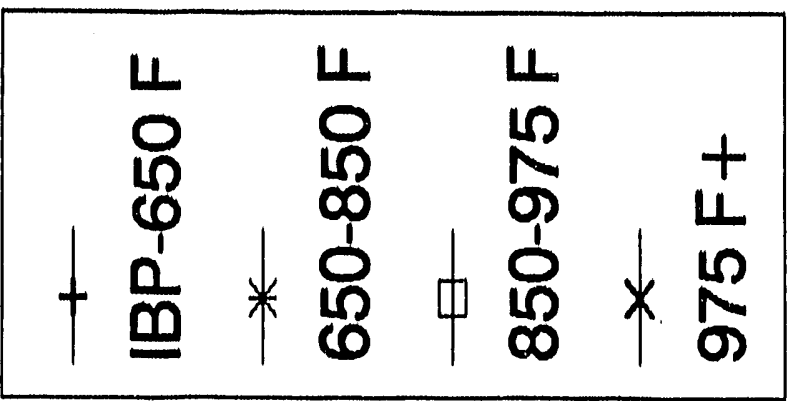

FIGURE 4

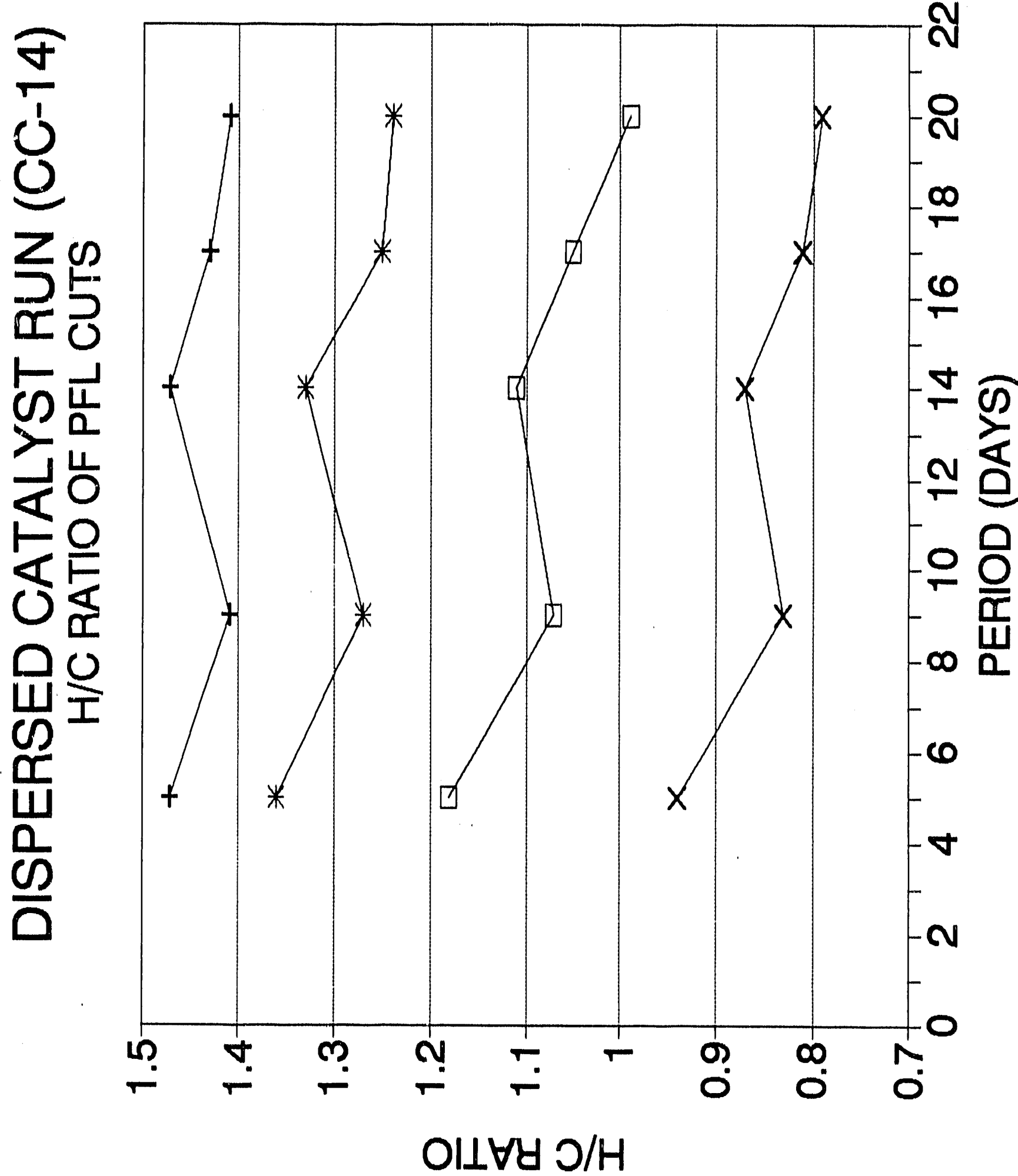




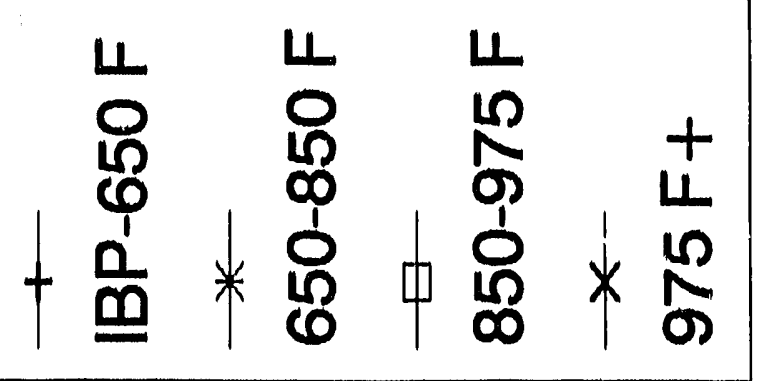

FIGURE 5

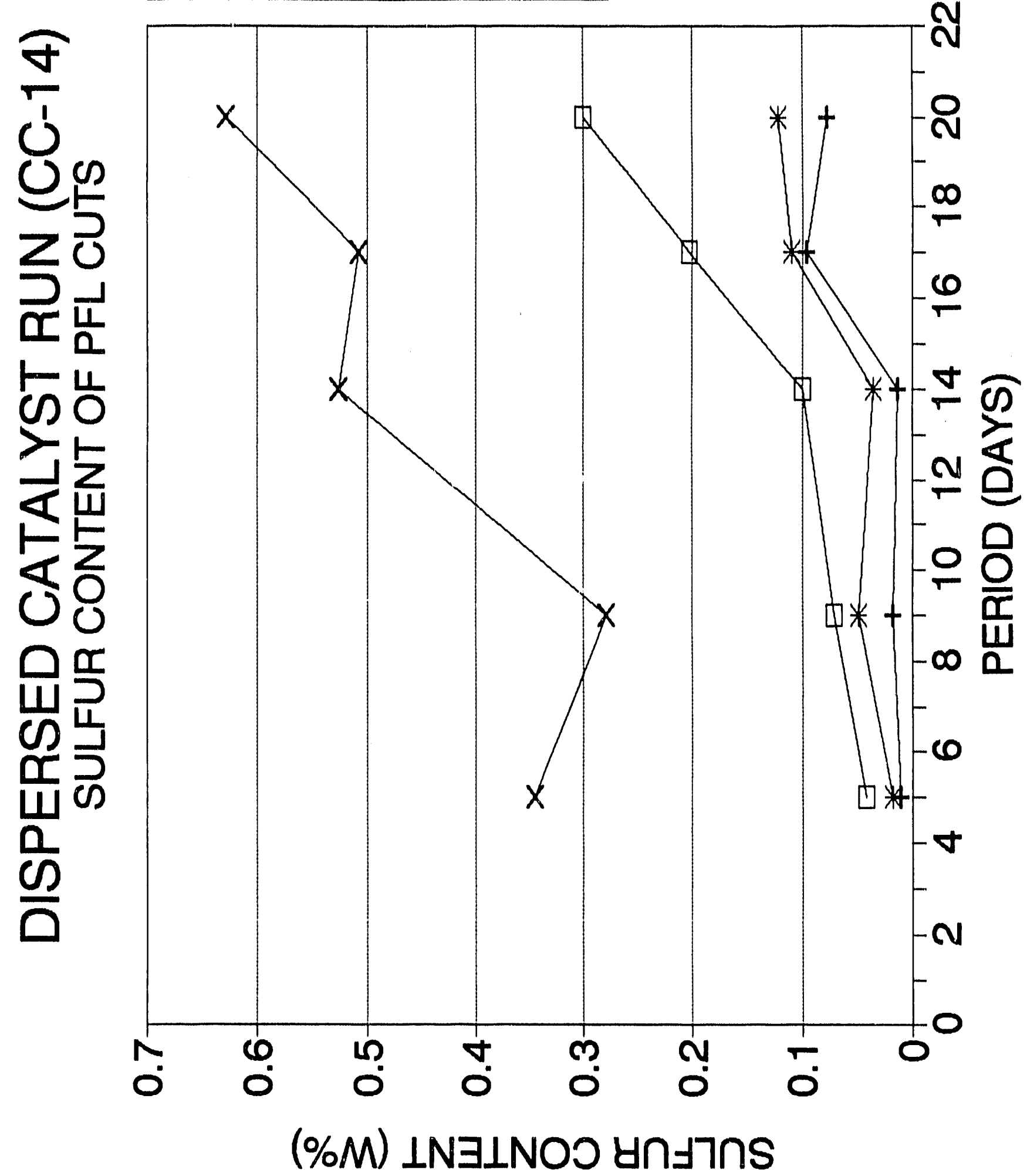


FIGURE 6

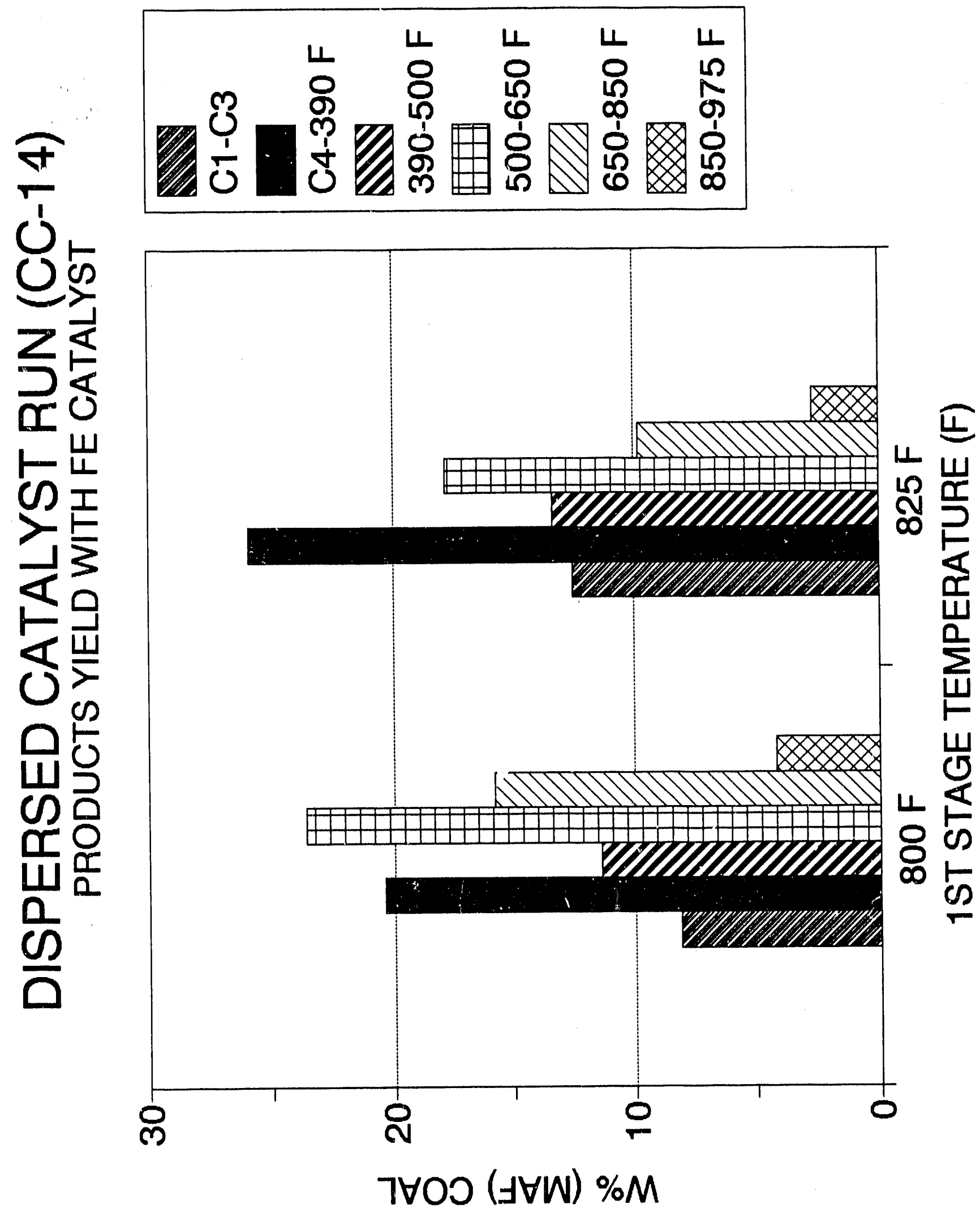


TABLE 7

\section{ANALYSIS OF ATMOSPHERIC OVERHEADS}

$\begin{array}{lccccc}\text { Condition } & 1 & 2 & 3 & 4 & 5 \\ \text { API Gravity } & 23.9 & 25.0 & 25.8 & 23.0 & 22.9 \\ \text { Carbon, W\% } & 87.4 & 87.2 & 87.0 & 87.0 & 86.9 \\ \text { Hydrogen, W\% } & 11.6 & 11.4 & 11.7 & 11.2 & 11.1 \\ \text { Nitrogen, W\% } & 0.14 & 0.19 & 0.15 & 0.2 & 0.25 \\ \text { Sulfur, W\% } & <0.01 & 0.02 & 0.04 & 0.11 & 0.13 \\ & & & & & \\ \text { H/C Ratio } & 1.60 & 1.57 & 1.61 & 1.55 & 1.53 \\ \text { Watson Factor } & 10.8 & 10.8 & 10.8 & 10.7 & 10.7\end{array}$




\section{SUMMARY AND CONCLUSIONS}

The iron-based chemically dispersed catalyst performed very well with distillate yields $\mathrm{C}_{4}-975^{\circ} \mathrm{F}$ of over $75 \mathrm{~W} \%$ of MAF coal with the first stage at $800^{\star} \mathrm{F}$ and the second ebullated-bed stage at $775^{\circ} \mathrm{F}$. Increasing the thermal severity to $825^{\circ} \mathrm{F}$ lowered the distillate yield and increased hydrogen consumption by producing more $\mathrm{C}_{1}-\mathrm{C}_{3}$ gases. Molybdenum based dispersed catalyst appears to yield better or equivalent performance with respect to residuum conversion and product quality; however, the relative performance may be over shadowed by deactivation of the supported catalyst in the ebullated-bed reactor.

Further optimization of the $\mathrm{FeOOH}$ catalyst formulation and operating conditions are warranted based on the results of this study. The yields in condition 1 approach the maximum obtained at HRI with two ebullated-bed reactor stages. See Table 8 for a comparison, although the coal shipments, time periods and cleaning techniques differ, the overall performance is similar.

\section{RECOMMENDATIONS}

Following the complete analysis of the spent ebullated-bed catalyst from this study and a complete metals balance, further studies to optimize operating conditions with Illinois coal are recommended. In addition the activity of this chemically dispersed iron catalyst should be investigated with sub-bituminous coal, a coal more difficult to convert but one that produces a more easily convertible residuum. 
TABLE 8

\section{A COMPARISON ILLINOIS \#6 COAL PHOCESSING WITH FeOOH CATALYST AND SUPPORTED CATALYSTS'}

Catalyst

Process

Catalyst Age, Ibs coal//b cat. Stage 2

Reaction Temperature, ${ }^{\circ} \mathrm{F}$

Pretreater (First Stage)

Second Stage

Third Stage

Performance, W\% MAF Coal

$\mathrm{C}_{4^{-9}} 975^{\circ} \mathrm{F}$

$975^{\circ} \mathrm{F}^{+}$Conversion

Hydrogen Consumption, W\%

Coal Conversion
$\mathrm{FeOOH}$

Pretreat Stage

First Stage Back-

Mixed

Second Stage-

Ebullated

145

233

525

800

775

750

800

75.1

76.2

88.0

90.2

7.5

7.4

94.0

95.4

'Different Shipments of Illinois \#6 Coal. 


\section{IASK 4 - MINI-PDU SCALE-UP}

\section{Preparations}

Work commenced on the design and purchase of components of the U.S. Filter Installation, Slurry Mix Tank Ventilation System, Gas and Oll Purge System Improvements, DMDS Feed Station and new reactor configuration.

\section{TASK 5 - TECHNICAL ASSESSMENT}

\section{Process Modelling}

A PDU Run Plan for the Extinction Recycle of Black Thunder Coal is being prepared using the latest process models derived from Bench-Scale and Micro-Scale Studies. 


\section{TASK 6 - ADMINISTRATION}

In the balance of the current contract the PDU scale-up demonstration run remains. Topical reports for the Bench-Scale and Laboratory-Scale Studies are being prepared.

A paper entitled "CTSLTM Catalytic Two-Stage Liquefaction Coupled with Coal Cleaning" was presented at the 20 1st National ACS Meeting in Atlanta Georgla on April 14-19, 1991. A paper entitled "Recent Advances in Direct Coal Liquefaction was presented at the 16th International Conference on Coal \& Slurry Technologies on April 22-25, 1991,

The attached schedule shows the run actlvities for the remainder of the contract. 

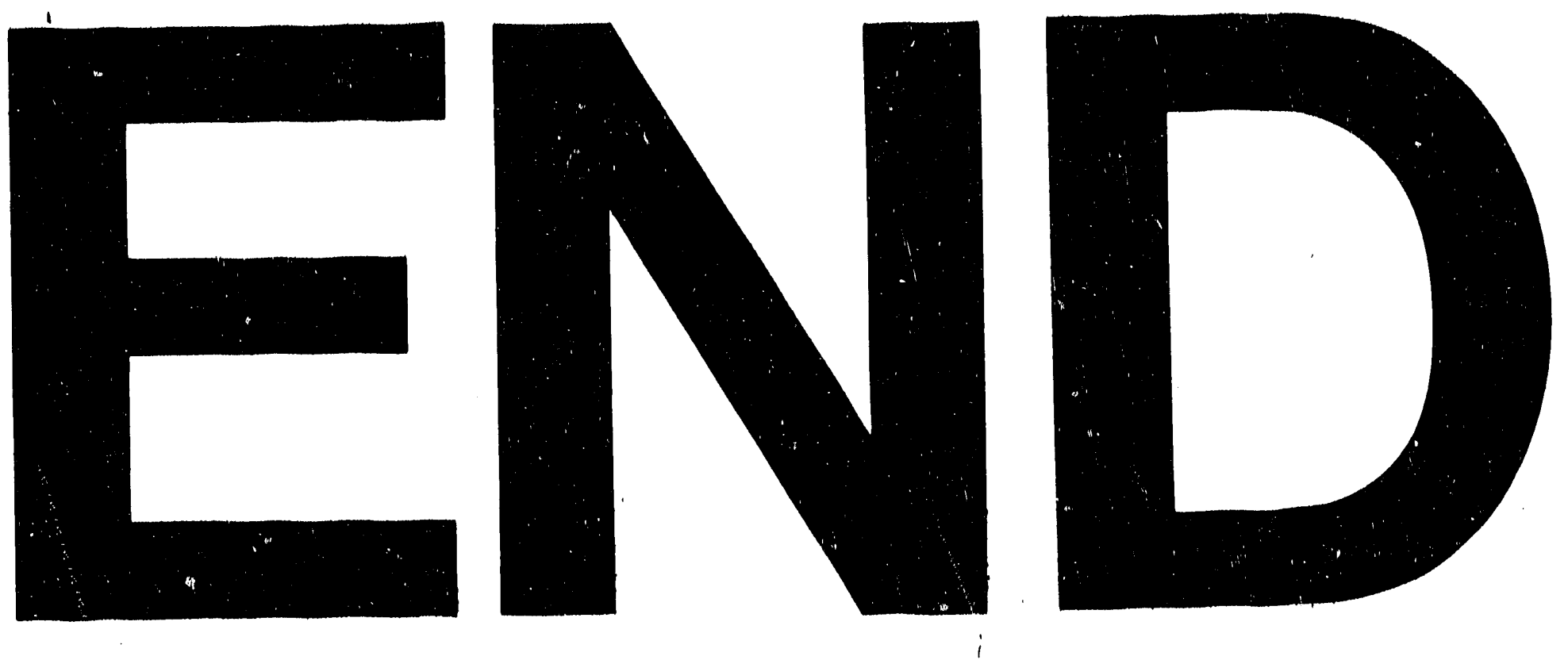

Fintix
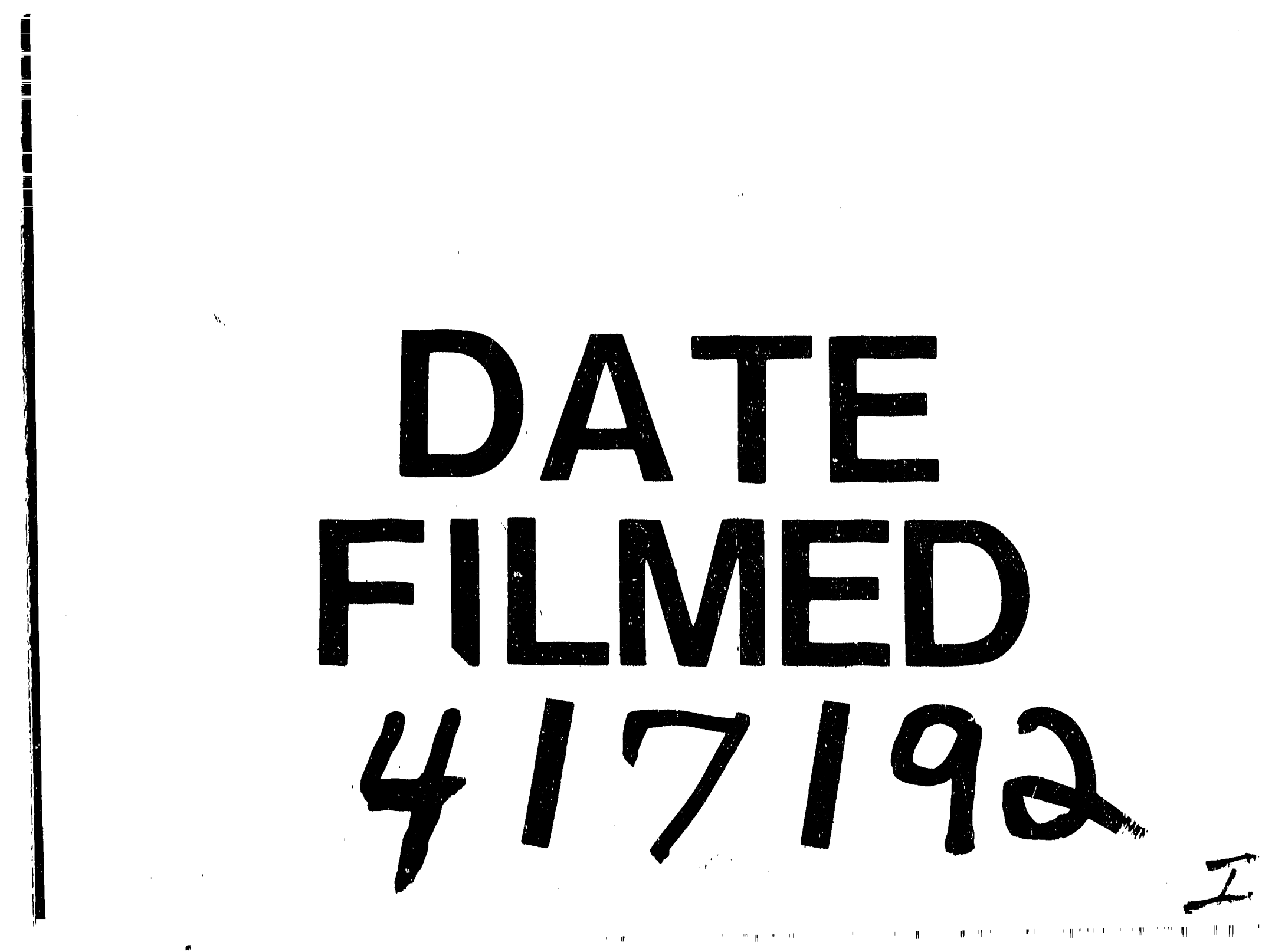
